\title{
Ned-19 inhibition of parasite growth and multiplication suggests a role for NAADP mediated signalling in the asexual development of Plasmodium falciparum
}

\author{
Pablo Suárez-Cortés ${ }^{1,2 \dagger}$, Guido Gambara ${ }^{3 \dagger}$, Annarita Favia ${ }^{3,4}$, Fioretta Palombi ${ }^{3}$, Pietro Alano ${ }^{1 *}$ \\ and Antonio Filippini ${ }^{3^{*}}$
}

\begin{abstract}
Background: Although malaria is a preventable and curable human disease, millions of people risk to be infected by the Plasmodium parasites and to develop this illness. Therefore, there is an urgent need to identify new anti-malarial drugs. $\mathrm{Ca}^{2+}$ signalling regulates different processes in the life cycle of Plasmodium falciparum, representing a suitable target for the development of new drugs.

Results: This study investigated for the first time the effect of a highly specific inhibitor of nicotinic acid adenine dinucleotide phosphate (NAADP)-induced $\mathrm{Ca}^{2+}$ release (Ned-19) on P. falciparum, revealing the inhibitory effect of this compound on the blood stage development of this parasite. Ned-19 inhibits both the transition of the parasite from the early to the late trophozoite stage and the ability of the late trophozoite to develop to the multinucleated schizont stage. In addition, Ned-19 affects spontaneous intracellular $\mathrm{Ca}^{2+}$ oscillations in ring and trophozoite stage parasites, suggesting that the observed inhibitory effects may be associated to regulation of intracellular $\mathrm{Ca}^{2+}$ levels.

Conclusions: This study highlights the inhibitory effect of Ned-19 on progression of the asexual life cycle of $P$. falciparum. The observation that Ned-19 inhibits spontaneous $\mathrm{Ca}^{2+}$ oscillations suggests a potential role of NAADP in regulating $\mathrm{Ca}^{2+}$ signalling of $P$. falciparum.
\end{abstract}

Keywords: Ned-19, NAADP, Malaria, Calcium signalling, Plasmodium falciparum, NAADP receptor, Antimalarial drugs, P. falciparum development

\section{Background}

With 3.3 billion of people at risk to be infected and an estimated death toll of 429,000 in 2015 [1] malaria remains a great threat in tropical countries. Artemisinin combination therapies, although highly effective, have met with the development of parasite resistance in recent

\footnotetext{
*Correspondence: pietro.alano@iss.it; antonio.filippini@uniroma1.it

†Pablo Suárez-Cortés and Guido Gambara contributed equally to this work

${ }^{1}$ Dipartimento di Malattie Infettive, Istituto Superiore di Sanità, Viale Regina Elena n. 299, 00161 Rome, Italy

3 Department of Anatomy, Histology, Forensic Medicine and Orthopedics,

Section of Histology and Medical Embryology, Sapienza University

of Rome, Rome, Italy

Full list of author information is available at the end of the article
}

years, exacerbating the need for the identification of new anti-malarial drugs [2].

In Plasmodium falciparum, $\mathrm{Ca}^{2+}$ signalling regulates different physiological processes involved in the life cycle of parasite, such as erythrocyte invasion [3, 4], merozoite egress from the infected erythrocyte [5] and parasite development [6]. As well as in higher eukaryotic cells, different $\mathrm{Ca}^{2+}$ stores have been found in Plasmodium: endoplasmic reticulum, acidocalcisomes, mitochondria and the digestive vacuole. Acidocalcisomes are acidic organelles rich in $\mathrm{Ca}^{2+}$ and other cations bound to phosphate polymers. $\mathrm{A} \mathrm{Ca}^{2+}$-ATPase, a bafilomycin-sensitive vacuolar $\mathrm{V}-\mathrm{H}^{+}$-ATPase, a V-H $\mathrm{H}^{+}$-PPase and a $\mathrm{Ca}^{2+}-\mathrm{H}^{+}$ antiporter localize on the membrane of these organelles, 
regulating $\mathrm{Ca}^{2+}$ balance [7]. It has been proposed that another acidic organelle of $P$. falciparum, the food vacuole, could be a $\mathrm{Ca}^{2+}$ store sensitive to thapsigargin, bafilomycin and $\mathrm{NH}_{4} \mathrm{Cl}$ [8]. $\mathrm{Ca}^{2+}$ homeostasis in Plasmodium is mainly regulated by two $\mathrm{Ca}^{2+}$-ATPase, the thapsigargin-insensitive PfATP4 [9] and the thapsigargin-sensitive sarco/endoplasmic reticulum $\mathrm{Ca}^{2+}$-ATPase (SERCA) orthologue PfATP6 [10]. Scheibel and co-workers showed that both $\mathrm{Ca}^{2+}$ and calmodulin antagonists inhibit the growth of P. falciparum [11]. Moreover, the identification of SERCA as a target of artemisinins [10] highlights the crucial role of $\mathrm{Ca}^{2+}$ signalling in the life cycle of the parasite.

In higher eukaryotic cells, different intracellular second messengers finely regulate the spatio-temporal fluctuation of cytosolic $\mathrm{Ca}^{2+}$ concentration, mobilizing calcium from different intracellular stores. Inositol 1,4,5-bisphosphate (IP3) [12], cyclic ADP-ribose (cADPR) [13] and nicotinic acid adenine dinucleotide phosphate (NAADP) [14] have been so far identified as $\mathrm{Ca}^{2+}$-mobilizing second messengers in higher eukaryotic cells. The second messenger NAADP was described for the first time as a potent $\mathrm{Ca}^{2+}$ mobilizing agent in sea urchin eggs [14] and subsequently in ascidian and starfish oocytes [15, 16], in plants [17] and in higher eukaryotic cells [18-21], suggesting a highly conserved feature in evolution for this molecule.

In Apicomplexa, second messengers involved in $\mathrm{Ca}^{2+}$ mobilization from intracellular organelles have been poorly investigated. At present only a few works have investigated the role of IP3 and cADPR in $\mathrm{Ca}^{2+}$ release in P. falciparum [22-24] and none focused on NAADP, possibly for the absence in the parasite genome of sequences homologous to the putative two pore channels (TPCs) NAADP-receptor. Recently, Ned-19 has been identified by virtual screening as a specific inhibitor of NAADPinduced calcium signalling in sea urchin eggs and pancreatic beta cells, and was shown to bind NAADP receptors as a fluorescent probe [25]. Subsequently, Ned-19 mediated $\mathrm{Ca}^{2+}$ signalling inhibition and its biological effects have been reported in different mammalian cells. Ned19 has been shown to inhibit histamine-induced secretion of von Willebrand factor (vWF) in endothelial cells [20], endothelin-1 (ET-1)-induced contraction of smooth muscle cells [26], NAADP-induced acrosome reaction in mammalian spermatozoa [27] and exocytosis of cytolytic granules in cytotoxic T Lymphocytes and VEGF-induced neoangiogenesis $[28,29]$.

The aim of this study was to investigate the effect of Ned-19 on the blood stage development of P. falciparum. Results show for the first time that Ned-19 specifically impairs both the growth and the ability to transform into multinucleate schizonts of the asexual trophozoite stages, suggesting a crucial role of NAADP in life cycle progression. This work also shows that Ned-19 inhibits spontaneous $\mathrm{Ca}^{2+}$ oscillations in early ring and trophozoite stages, which also suggests an important role of NAADP in $\mathrm{Ca}^{2+}$ homeostasis of $P$. falciparum.

\section{Methods \\ Plasmodium falciparum parasites and cultures}

Parasites from clone 3D7 [30] were cultured in $0^{+}$human red blood cells at 5\% haematocrit in RPMI 1640 plus hypoxanthine $50 \mathrm{mg} / \mathrm{mL}$, HEPES $25 \mathrm{mM}, 0.225 \%$ sodium bicarbonate and $10 \mathrm{mg} / \mathrm{mL}$ gentamicin, supplemented with $10 \%$ heat inactivated human serum. Parasites were kept at $37{ }^{\circ} \mathrm{C}$, in a $2 \% \mathrm{O}_{2}, 5 \% \mathrm{CO}_{2}$ and $93 \% \mathrm{~N}_{2}$ atmosphere. Percoll cushion and sorbitol treatment for parasite synchronization were performed as described [31, 32] previously. In parasite synchronization, sorbitol treatment of newly invaded parasites from Percoll purified schizonts was performed $3 \mathrm{~h}$ after Percoll treatment to obtain a parasite synchronization window of maximum $3 \mathrm{~h}$. For gametocyte production, asynchronous parasites were grown to high parasitaemia $(>8 \%)$ and culture medium was doubled at this point. The day after, $50 \mathrm{mM} \mathrm{N}$-acetylglucosamine was added to medium and maintained for 3 days, until no asexual parasites were detected in the culture. Stage II gametocytes were detected $48 \mathrm{~h}$ after the addition of $\mathrm{N}$-acetylglucosamine, while mature stage $\mathrm{V}$ appeared from 9 days after the treatment.

Parasitaemia was measured through Giemsa staining of culture blood smears (counting of at least $2000 \mathrm{RBCs}$ ) or FACS using CYBRGreen staining as previously described (counting of at least 50,000 cells) [33]. FACSAria I (BD Biosciences, Erembodegem, Belgium) equipped with three lasers (488, 635 and $407 \mathrm{~nm}$ violet solid state laser) was used to determine parasitaemia to a precision of $0.1 \%$. The results were analyzed by BD FACSDiva Software version 6.1.3 (BD Biosciences).

\section{Ned-19 and Ned-20 treatments}

Ned-19 (Tocris bioscience) was resuspended in a stock solution of sterile dimethyl sulfoxide (DMSO) at $100 \mathrm{mM}$ and kept at $-20{ }^{\circ} \mathrm{C}$ until added to the Plasmodium cultures at the specified concentrations. In the case of Ned-20 the stock solution was kindly provided by Grant Churchill (Oxford University) at $10 \mathrm{mM}$ and kept at $-20{ }^{\circ} \mathrm{C}$ until use. Control cultures were incubated with a DMSO concentration equivalent to that of the treated cultures. Differences in parasitaemia between treated and untreated cultures were evaluated through Student's t test. 


\section{Microscopy}

Parasite cultures were incubated with $200 \mu \mathrm{M}$ Ned-19 and $1 \mu \mathrm{M}$ Lysotracker Green DND-26 (ThermoFisher Scientific) for $30 \mathrm{~min}$ at $37{ }^{\circ} \mathrm{C}$ in agitation and observed with a fluorescence microscope. A Zeiss Observer.Z1 inverted microscope was used to visualize live samples. Images were acquired using a Zeiss AxioCam MRm Rev. 3 FireWire camera through a Zeiss C-Apochromat 63x/1, 20 objective. Filters used to detect fluorescence were EX: 365-395, EM: 445-450 (Ned-19) and EX: 440-470, EM: 525-550 (Lysotracker Green DND-26). Giemsa-stained smears were examined to confirm stages of the synchronized parasites: proportions $>90 \%$ of trophozoites, schizonts and ring forms were, respectively, observed at 32, 46 and $48 \mathrm{~h}$ after synchronization.

\section{Electron microscopy}

Parasite culture samples enriched in infected red blood cells by MACS (Magnetic-activated cell sorting) were fixed overnight in cold $2.5 \%$ glutaraldehyde in $0.1 \mathrm{M}$ cacodylate buffer, postfixed in $2 \%$ osmium tetroxide for $2 \mathrm{~h}$ and treated for $30 \mathrm{~min}$ with $1 \%$ tannic acid in $0.05 \mathrm{M}$ cacodylate buffer. Pellets were then dehydrated in ethanol and processed for Epon embedding. Ultrathin sections were contrasted in lead hydroxide and analyzed in a Hitachi 7000 transmission electron microscope.

\section{Calcium imaging}

In $\mathrm{Ca}^{2+}$ imaging experiments, protocol was adapted from [6], using the ratiometric Fura-2-AM as calcium reporter. Samples from cultures at high parasitaemia (5-10\%) of the desired parasite stage were generated through parasite synchronization as follows: for early rings, parasites were harvested $50 \mathrm{~h}$ after the initial Percoll treatment, while for early trophozoites parasites were harvested $26 \mathrm{~h}$ after Percoll treatment. Cultures where then washed in BSA - medium for $\mathrm{Ca}^{2+}$ imaging (RPMI 1640 medium without phenol red supplemented with 25 mM HEPES, $24 \mathrm{mM}$ sodium bicarbonate, $0.5 \mathrm{~g} / \mathrm{L}$ L-glutamine and $50 \mathrm{mg} / \mathrm{L}$ hypoxanthine) and resuspended at 5\% haematocrit in loading medium [BSA- medium supplemented with 1:100 PowerLoad (ThermoFisher Scientific)] with $3 \mu \mathrm{M}$ Fura-2-AM (ThermoFisher Scientific) at $37^{\circ} \mathrm{C}$ for $150 \mathrm{~min}$ in agitation. Loading medium was then washed away and cells were resuspended at $2.5 \%$ haematocrit in $\mathrm{BSA}+$ medium [BSA - medium supplemented with $0.5 \%$ Albumax I and $25 \mathrm{mg} / \mathrm{mL}$ gentamicin (Sigma)]. Ned-19 $100 \mu \mathrm{M}$ or $0.1 \%$ DMSO was added to $1 \mathrm{~mL}$ of this cell suspension. This was plated in glass-bottomed $30 \mathrm{~mm}$ dishes previously coated with poly-L-lysine and incubated in a $2 \% \mathrm{O}_{2}, 5 \% \mathrm{CO}_{2}$ and $93 \% \mathrm{~N}_{2}$ atmosphere for $45 \mathrm{~min}$. Unbound cells were washed by gently rinsing the surface of the plate and substituting supernatant with
BSA + medium with Ned-19 or DMSO. Medium volume was then adjusted to $1 \mathrm{~mL}$ of BSA+ with Ned-19 or DMSO. This treatment resulted in cells treated with Ned19 or DMSO for at least $45 \mathrm{~min}$ prior to the beginning of measurements, and the Ned-19 and DMSO treatments being kept during calcium imaging.

$\mathrm{Ca}^{2+}$ mobilization was measured in presence or absence of Ned-19. Plates with Fura-2-loaded cells were placed into a culture chamber at $37{ }^{\circ} \mathrm{C}$ on the stage of an inverted fluorescence microscope (Nikon, TE2000E), connected to a cooled CCD camera (512B Cascade, Princeton Instruments, AZ). Samples were illuminated alternately at 340 and $380 \mathrm{~nm}$ using a random access monochromator (Photon Technology International, NJ) and emission was detected using a $510 \mathrm{~nm}$ emission filter. Images ( 1 set of emission at 340 and $380 \mathrm{~nm}$ every $1.5 \mathrm{~s}$ ) were acquired using Metafluor software (Universal Imaging Corporation, Downingtown, PA).

Images were analysed by generating square $4 \times 4 \mathrm{~mm}$ ROIs (region of interest) encompassing a single parasite and recording the intensity of the emission for the ROI at 340 and $380 \mathrm{~nm}$. Background was normalized for each ROI using a ROI the size of the full image, and ratio (R) was calculated as $\mathrm{F}_{(340)} / \mathrm{F}_{(380)}$ for each ROI and timepoint, obtaining time-courses for each ROI. $R$ values were then normalized as $\mathrm{R} / \mathrm{R}_{\min }-1$.

OCTAVE free software with the script findpeaksfit.m by T.C. O'Haver [34] was used to identify and measure height of peaks, given as $\mathrm{R} / \mathrm{R}_{\min }-1$ values. Oscillation series were subdivided into fragments of $100 \mathrm{~s}$ each and script was run with settings as follows: $x, y$, SlopeThreshold $=0.0005$, AmpThreshold $=0$, smoothwide $=3$, peakgroup $=3$, smoothtype $=3$, peakshape $=1$, extra $=0$, NumTrials $=0$, autozero $=1$, fixedparameters $=0$, plots $=0$. Differences between the height of peaks in DMSO and Ned-19 treated parasites were evaluated through unpaired Student's t test analysis. For DMSO treated rings, $\mathrm{N}$ (number of time-courses) $=6, \mathrm{n}$ (total number of peaks detected) $=622$. For Ned-19 treated rings, $\mathrm{N}=6, \mathrm{n}=265$. In the case of trophozoites, for DMSO treated parasites $\mathrm{N}=8, \mathrm{n}=349$, for Ned-19 treated parasites $\mathrm{N}=3, \mathrm{n}=150$.

\section{Results}

Ned-19 inhibits the asexual development of Plasmodium falciparum

To determine whether the highly selective NAADP antagonist Ned-19 affected the asexual cycle of $P$. falciparum, the effects of this compound and of its inactive analogue Ned-20, unable to inhibit NAADP-mediated $\mathrm{Ca}^{2+}$ release in other organisms [35], were evaluated on synchronized early asexual stages of parasite clone 3D7, which were incubated for $48 \mathrm{~h}$ in the presence of Ned-19, 
Ned-20 or DMSO $(100 \mu \mathrm{M})$. The parasitaemia of the culture incubated with Ned-19 showed a fivefold reduction compared to the DMSO-treated parasites. In contrast, a

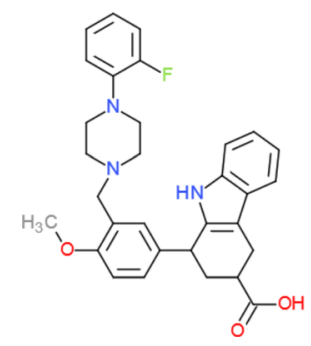

Ned-19

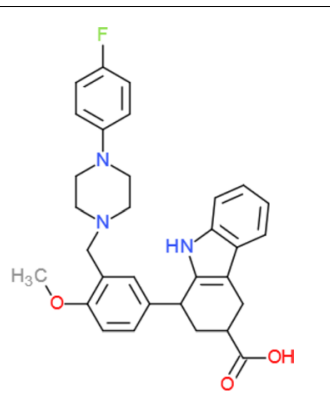

Ned-20
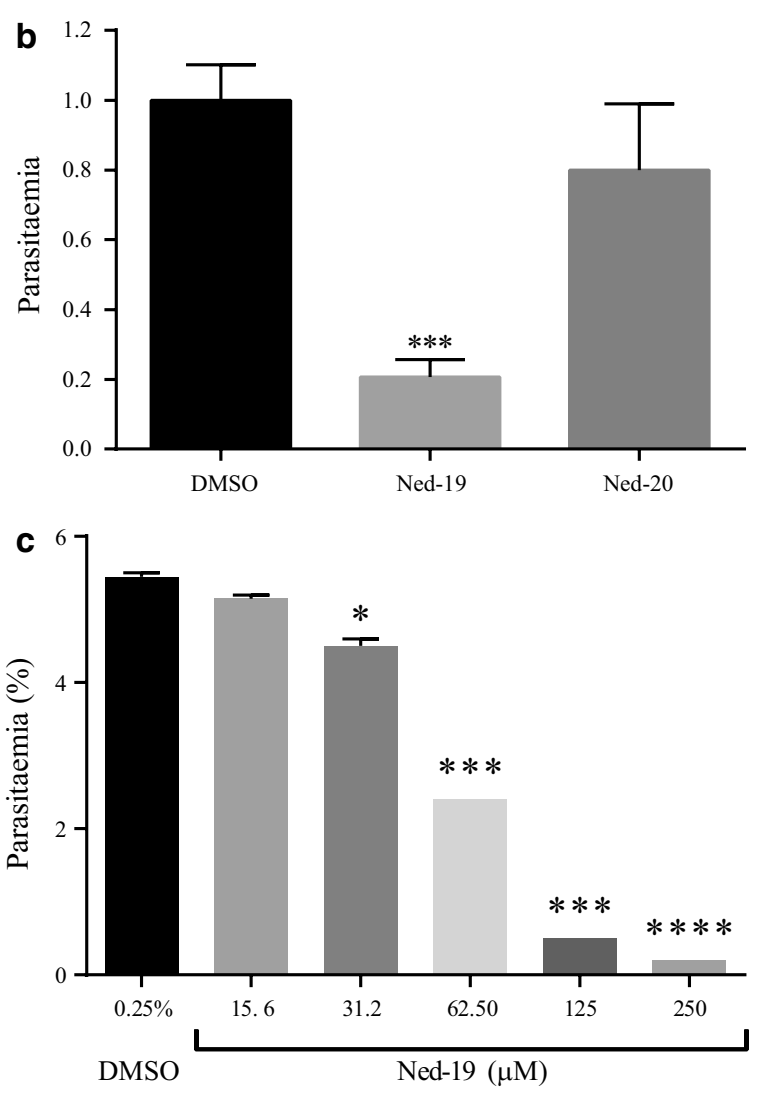

Fig. 1 Ned-19 specific blockage of P. falciparum asexual growth. a Structure of Ned-19 and of its inactive analogue Ned-20, adapted from Rosen et al. b Synchronous early ring stage parasites (initial parasitaemia $0.16 \%$ ) were cultured for $48 \mathrm{~h}$ in the presence of $100 \mu \mathrm{M}$ concentration of the indicated compounds. At the end of the incubation, parasitaemias were measured through Giemsa-stained preparations. Parasitaemia of the DMSO treated culture (1.08\%) was set as 1. $\mathrm{N}=3 .{ }^{* *} \mathrm{p}<0.001$. Error bar SEM. c Late asexual parasites ( $24 \mathrm{~h}$ post invasion, initial parasitaemia 1\%) were cultured with the indicated concentrations of Ned-19 for $24 \mathrm{~h}$. Parasitaemia was then measured through FACS counting of at least 50.000 cells per sample. $N=2$. ${ }^{*} p<0.05 ;{ }^{* * *} p<0.001 ;{ }^{* * *} p<0.0001$. Error bar range/2 the Ned-20 treated culture did not show a significant reduction in parasitaemia, supporting the specificity of Ned-19 in impairing the parasite asexual growth (Fig. 1b). Additional experiments showed that Ned-19 impairs parasite growth in a dose-dependent manner (Fig. 1c).

\section{Ned-19 blocks development of early trophozoites and prevents schizont maturation}

To pinpoint the stage(s) of the parasite life cycle affected by Ned-19, a time course spanning one parasite asexual cycle was performed. A tightly synchronized culture of newly invaded ring stage parasites (synchronization window of $3 \mathrm{~h}$ ) was produced and treated as described in Fig. 2. A control subculture was exposed to DMSO (subculture 1), one was treated with $100 \mu \mathrm{M} \mathrm{Ned-19}$ for the entire cycle (subculture 2), one for the initial $8 \mathrm{~h}$ only (subculture 3), and in five additional subcultures (4-8) Ned-19 was added at $8 \mathrm{~h}$ intervals, at $8,16,24,32$ and $40 \mathrm{~h}$ of the parasite asexual development.

Parasite numbers and morphology were determined in Giemsa stained smears at all time points of all subcultures. Results indicated that presence of Ned-19 limited to the first $8 \mathrm{~h}$ after parasite invasion, at the very early ring stage parasites (subculture 3), or after $40 \mathrm{~h}$, at the late schizont stage (subculture 8), did not affect the completion of the life cycle and the invasion of new red blood cells by the merozoites produced in schizogony. In contrast, parasite development was affected if Ned-19 was present between 8 and $40 \mathrm{~h}$ post-invasion. Timing and length of Ned-19 exposure were associated to some differences in the effects on the treated parasites. When ring stage parasites were exposed to Ned-19 from 0,8 , or $16 \mathrm{~h}$ post-invasion (subcultures 2,4 and 5), their development did not progress beyond the early trophozoite stages, which accumulated and were observable for the remaining $48 \mathrm{~h}$. When Ned-19 was added later in the asexual cycle, from 24 or $32 \mathrm{~h}$ of development (subcultures 6 and 7), the treated early trophozoite stages did not progress in development and accumulated as early schizonts. In subculture 7 a decrease in parasite number was also observed, indicating that incubation of Ned-19 with late trophozoite stages led to parasite cell disruption, unlike it was observed when Ned-19 was incubated with the ring stage parasites.

This experiment indicates that short-term exposure of parasites at the very early phase of the asexual cycle to Ned-19 is not sufficient to block development and, later in the cycle, Ned-19 does not directly affect schizogony and merozoite reinvasion. Ned-19 inhibitory activity is instead concentrated in the trophic part of the asexual cycle and in the development of the trophozoite into the schizont, suggesting that Ned-19 affects distinct cellular 
a
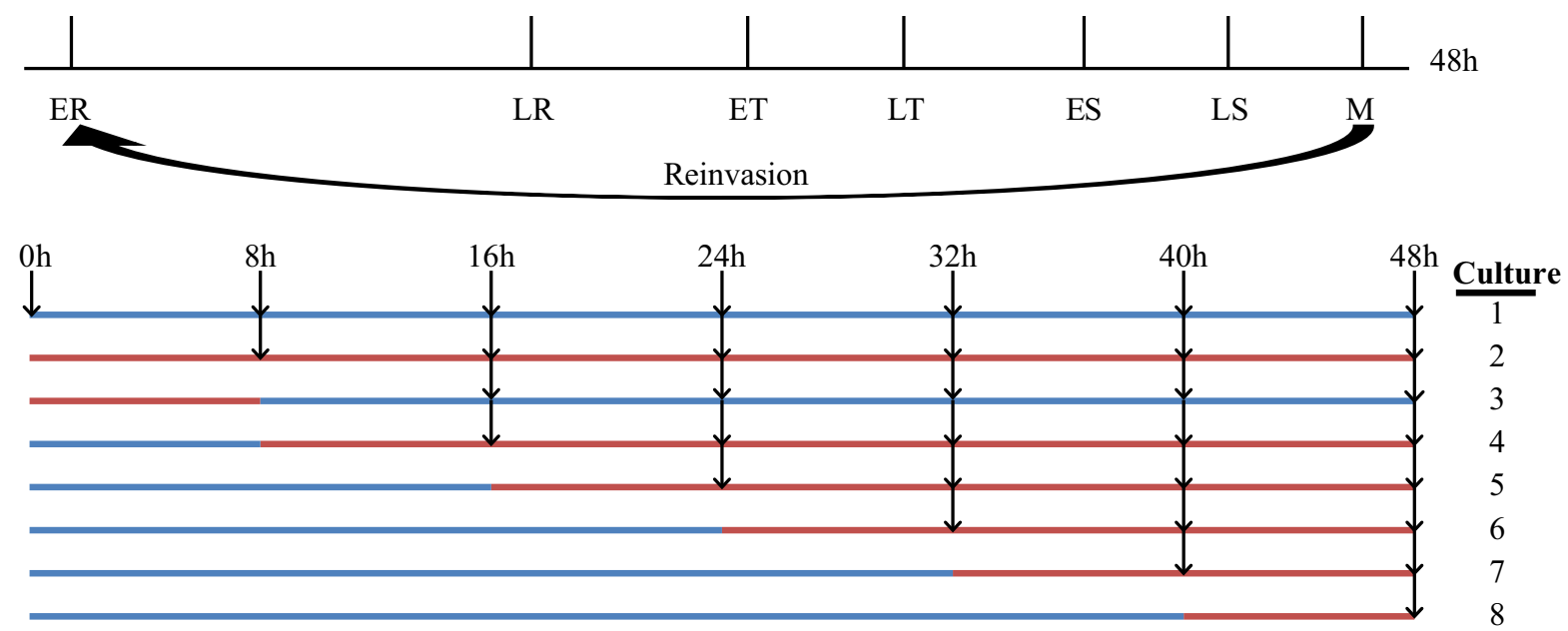

b
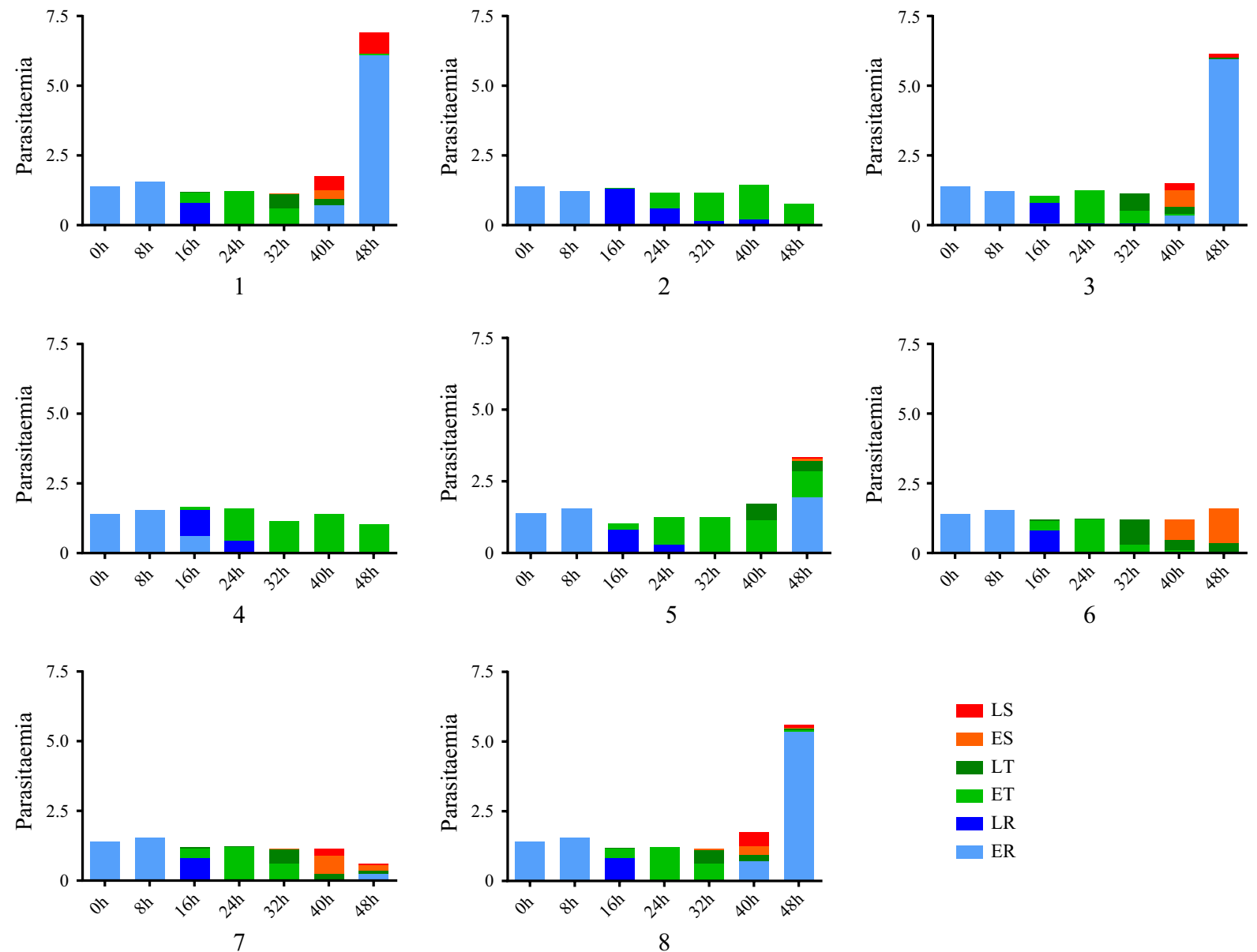

Fig. 2 Ned-19 activity on different stages of the P. falciparum asexual cycle. Synchronized ring stage parasites (initial parasitaemia 1.4\%) were used to yield subcultures, numbered 1-8, which were incubated with DMSO control (blue line) or exposed to $100 \mu \mathrm{M}$ Ned-19 (red line) at different times of the parasite asexual cycle. a Stages of the parasite asexual cycle. Black arrows indicate times at which the cultures were sampled. $\mathbf{b}$ Histograms showing parasitaemia and distribution of the different parasite stages for the cultures in each time-point. ER early rings, LR late rings, ET early trophozoites, LT late trophozoites, ES early schizonts, LS late schizonts. A representative sample of these forms is shown in Additional file 2: Figure S2 
processes in the ring and in the trophozoite stages of the asexual parasite.

To pinpoint the time at which Ned-19 blocks late asexual development, tightly synchronized late trophozoite stages (32 h after synchronization) were treated with $100 \mu \mathrm{M}$ Ned-19 at different times spanning a period from $12 \mathrm{~h}$ before to $2 \mathrm{~h}$ after schizogony, which occurred $44 \mathrm{~h}$ after invasion in the untreated control culture (Fig. 3). Parasite morphology and the number of ring stages resulting from successful merozoite reinvasion were measured. The experiment showed that Ned-19 treatment at 12, 10, 8 and 6 h before schizogony resulted in a low number of rings in the next cycle compared to the untreated cultures. This effect was less pronounced, but statistically significant, in the cultures treated 4 and $2 \mathrm{~h}$ before schizogony, whereas cultures in which Ned19 was added at the moment of schizogony showed no difference compared to the DMSO-treated controls. The partial effect observed at the time points immediately preceding schizogony may however be explained by the fact that the $3 \mathrm{~h}$ synchronization window used in this experiment would allow some of the parasites to reach the Ned-19 insensitive schizont stage at these time points. This experiment in conclusion confirms that Ned-19 alters the transition from late trophozoite to early schizont and the subsequent parasite maturation into a mature schizont, while it does not affect egress of the merozoites or their ability to reinvade uninfected red blood cells.

To investigate effects of Ned-19 treatment on parasite morphology, late asexual parasites were treated with 62.5 or $125 \mu \mathrm{M}$ Ned-19 and examined through Giemsa staining and electron microscopy after $6 \mathrm{~h}$ of incubation. Examination by light microscopy revealed an aberrant morphology of the late parasite stages, characterized by presence of unstained vacuoles or nuclei with abnormal morphology. These features were present in 48 and $60 \%$ of the parasites in the $62.5 \mu \mathrm{M}$ and the $125 \mu \mathrm{M}$ treatments, respectively (Additional file 1: Figure S1).

\section{Ned-19 localizes to acidic compartments in P. falciparum}

Ned-19 is a fluorescent compound and this property has been exploited to label and subcellularly localize the NAADP receptors [25]. To investigate the presence and subcellular localization of putative NAADP receptors in P. falciparum, live parasites incubated with $200 \mu \mathrm{M}$ Ned19 were examined by fluorescence microscopy. Results showed that Ned-19 fluorescence exhibited a diffuse pattern in the different stages of the asexual cycle and in gametocytes (Fig. 4a).

As Ned-19 localizes to acidic lysosome-like organelles in other cell types, Lysotracker Green DND-26, a dye marking membranes of acidic organelles, was used in co-localization experiments with Ned-19 (Fig. 4b, c). In this experiment a similar subcellular pattern of the Lysotracker and the Ned-19 fluorescence signals in both asexual and sexual parasites was observed, suggesting that Ned-19 accumulates in Lysotracker-positive compartments in P. falciparum. This may lead to speculate that putative parasite NAADP receptor(s) may localize in acidic compartments within the parasite, similarly to other organisms [36].

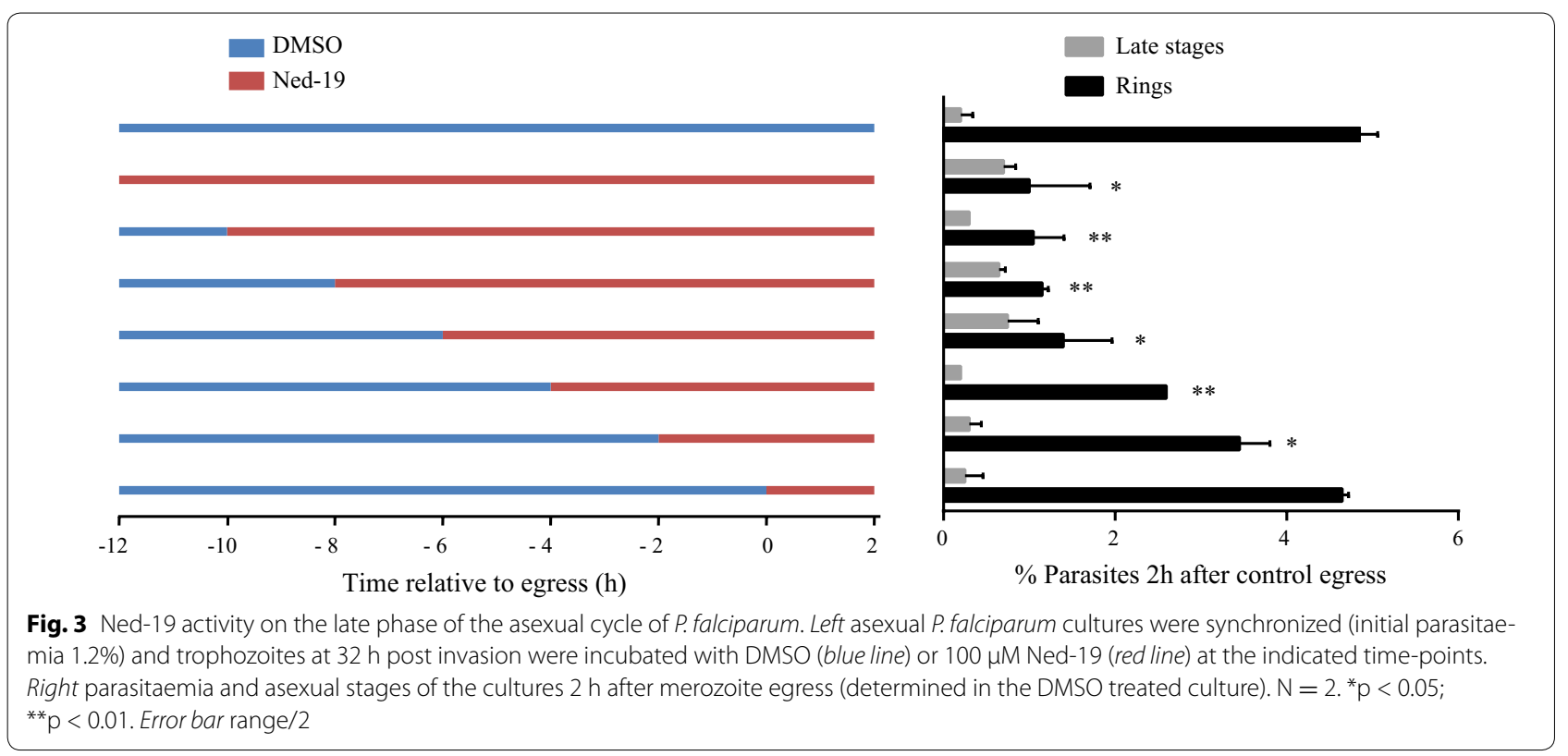



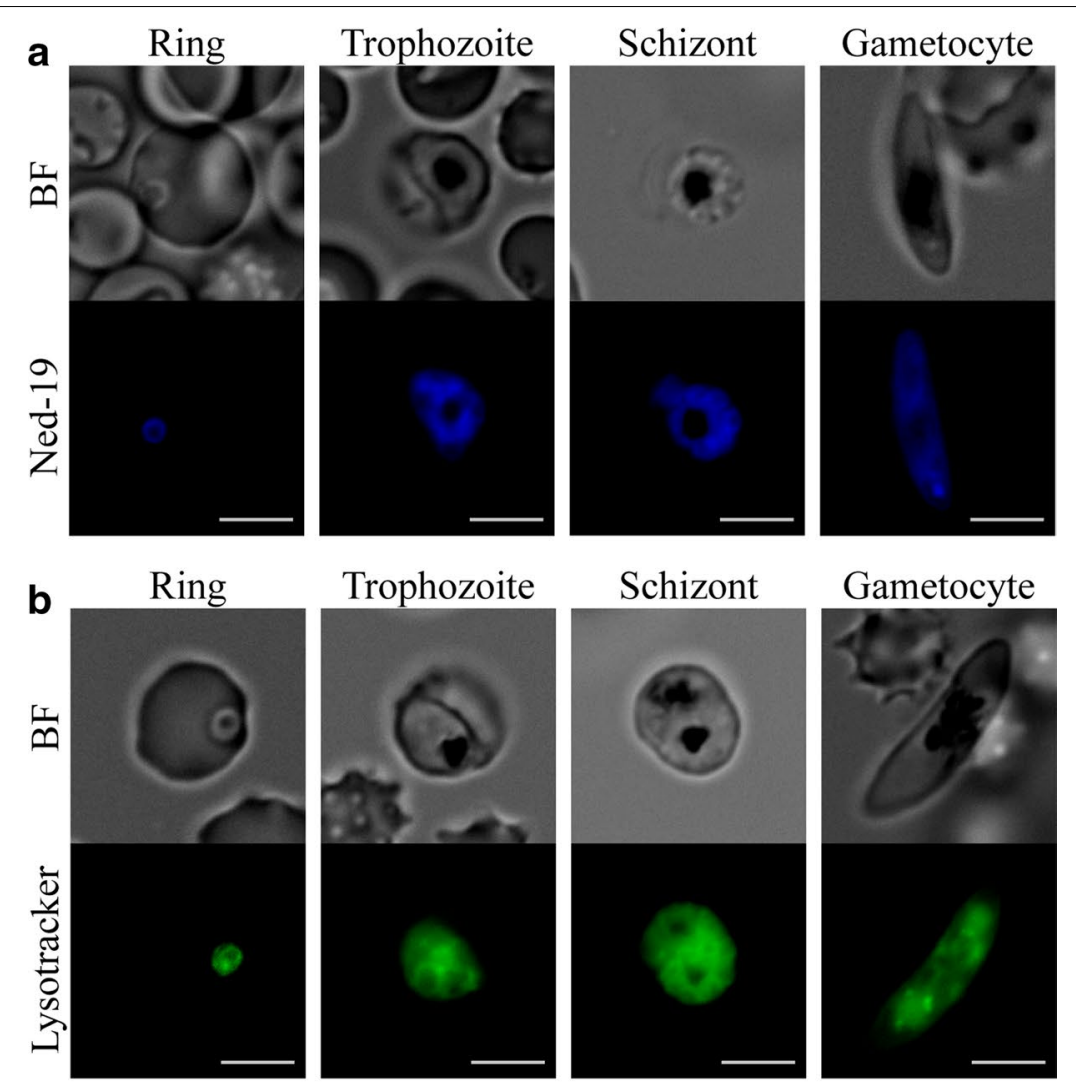

Gametocyte
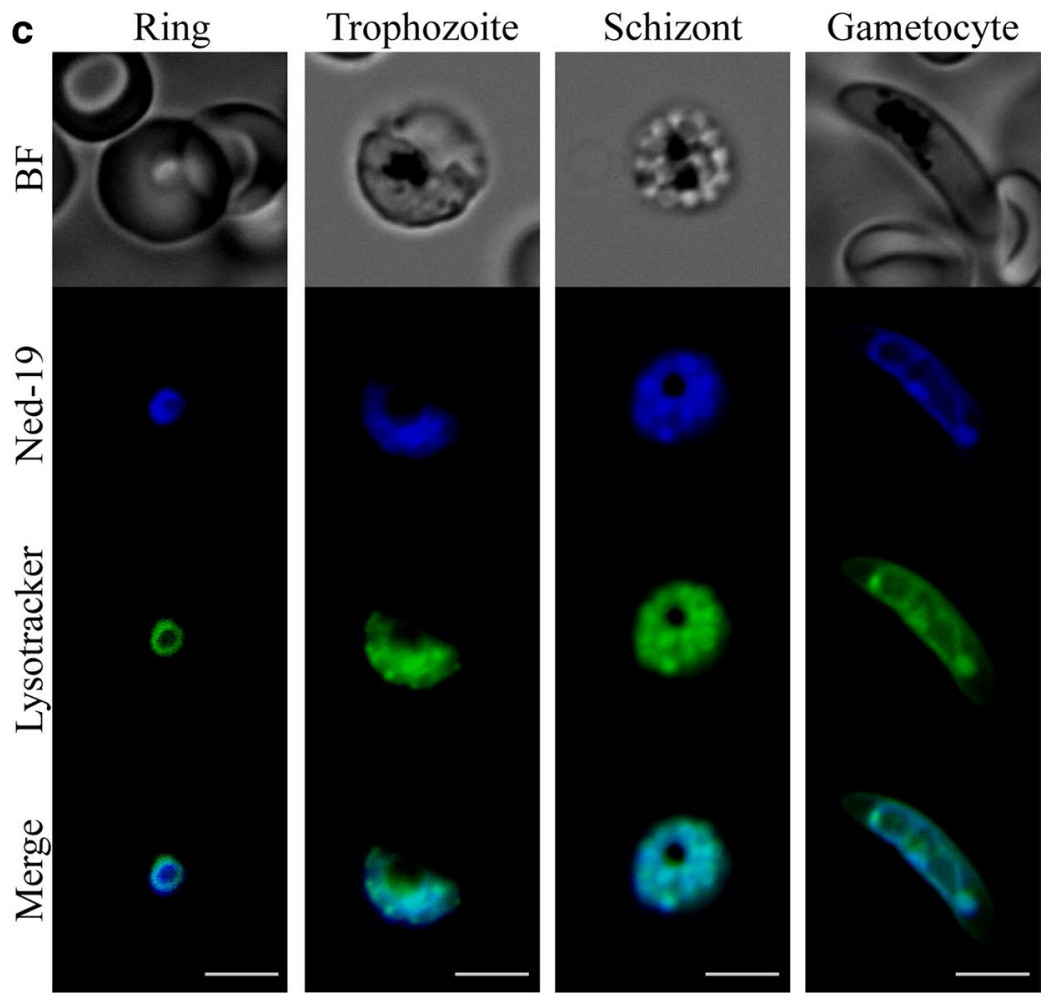

Fig. 4 Ned-19 colocalizes with Lysotracker in asexual and sexual parasites. a Parasites stained with $200 \mu \mathrm{M}$ Ned-19. b Parasites stained with $1 \mu \mathrm{M}$ Lysotracker. c Parasites stained with $200 \mu \mathrm{M}$ Ned-19 and $1 \mu \mathrm{M}$ Lysotracker. BF bright field. Scale bar $5 \mu \mathrm{m}$ 
Ned-19 inhibits spontaneous $\mathrm{Ca}^{2+}$ oscillations in early ring and early trophozoite stages

To determine whether Ned-19 affects $\mathrm{Ca}^{2+}$ homeostasis in P. falciparum, spontaneous oscillations in intracellular $\mathrm{Ca}^{2+}$ concentration $[6,37]$ were measured incubating synchronized early ring and early trophozoite stages loaded with the calcium indicator Fura-2-AM in the presence or absence of $100 \mu \mathrm{M}$ Ned-19. Oscillations in the intensity of the fluorescent signals were observed in treated and untreated parasites and the respective average peak heights were calculated, with values normalized to the minimum value in each measurement (Fig. 5a). R/ Rmin -1 for untreated early rings and trophozoites were $0.0202\left(\right.$ SEM $\left.4.64 \times 10^{-4}\right)$ and $0.0267\left(\right.$ SEM $\left.1.02 \times 10^{-3}\right)$ respectively, whereas in the Ned-19 treated parasites values were $0.01526\left(\mathrm{SEM} 3.82 \times 10^{-4}\right)$ and 0.02177 $\left(\right.$ SEM $9.14 \times 10^{-4}$ ) for early rings and for early trophozoites, respectively. The significantly smaller oscillations observed in the treated ring and trophozoite stages ( $p<0.0001$ and $\mathrm{p}=0.0029$, respectively) (Fig. 5b) indicate that spontaneous oscillations in free $\mathrm{Ca}^{2+}$ concentration are affected by Ned-19, supporting a specific effect of Ned-19 in P. falciparum $\mathrm{Ca}^{2+}$ regulation.

\section{Discussion}

This study investigated for the first time the effect of the NAADP antagonist Ned-19 on P. falciparum development, revealing that this compound inhibits the parasite asexual cycle and suggesting a potential role of NAADP in regulating $P$. falciparum $\mathrm{Ca}^{2+}$ signalling.

While the effects of inositol 1,4,5-bisphosphate (IP3)induced [22, 23], cyclic ADP-ribose (cADPR) and ATPinduced [38] $\mathrm{Ca}^{2+}$ release have been previously described in P. falciparum [24] and in Toxoplasma gondii [39], the role of NAADP in this process and in parasite physiology has never been investigated in apicomplexan parasites. Moreover, the receptors involved in second messengerinduced $\mathrm{Ca}^{2+}$ release are unknown, since the orthologue of both IP3 receptors (IP3Rs) and ryanodine receptors (RyRs) have not been identified and two pore channels (TPCs) NAADP-receptor homologous sequences have not been found in the genome of $P$. falciparum [40]. Results of the present work show that a highly specific inhibitor of NAADP-induced $\mathrm{Ca}^{2+}$ release (Ned-19) blocks the transition from early to late trophozoite stages and schizont maturation in P. falciparum, supporting the notion that $\mathrm{Ca}^{2+}$ signalling plays a crucial role in different
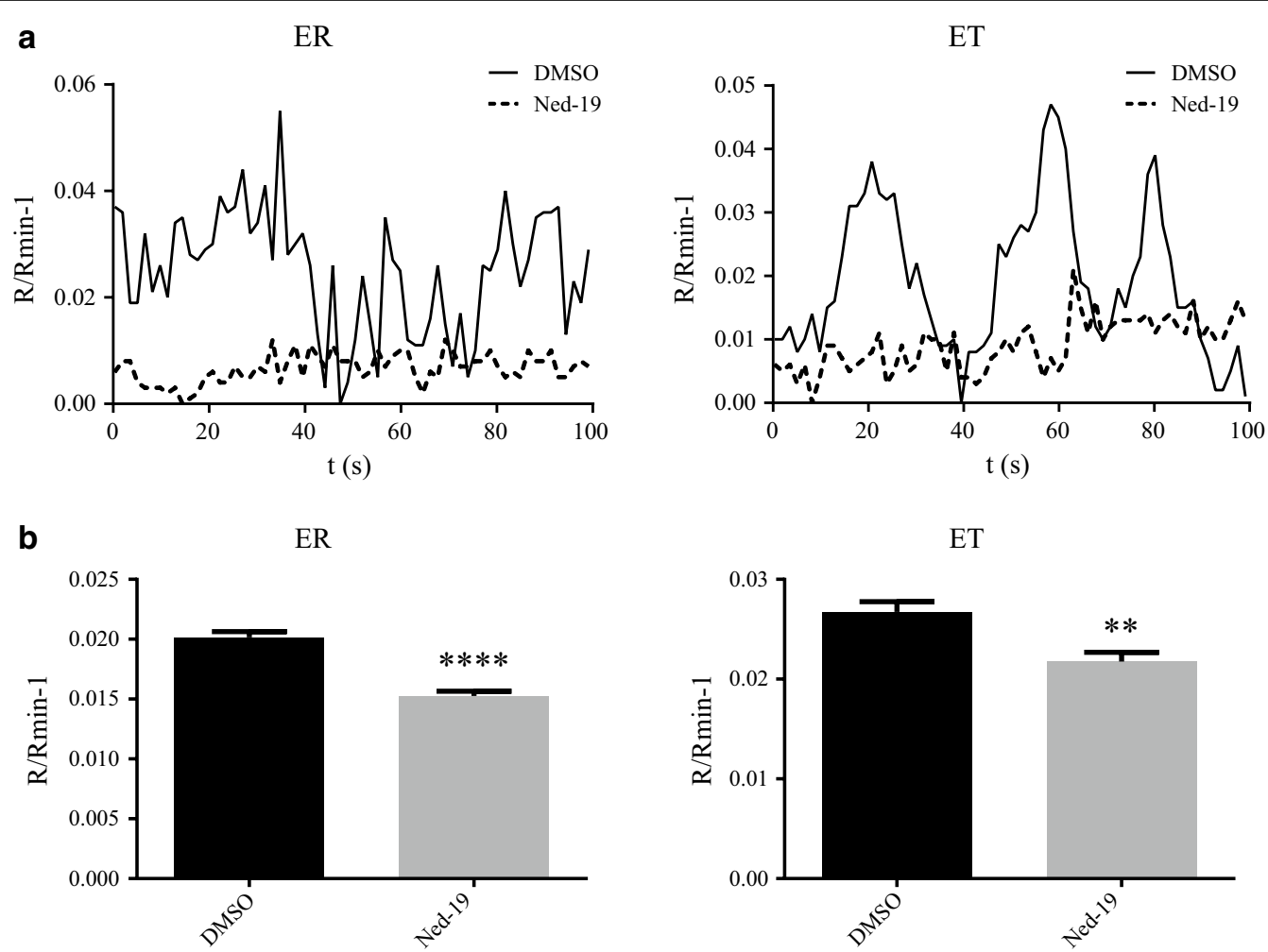

Fig. 5 Ned-19 inhibits spontaneous calcium oscillations in P. falciparum early rings and early trophozoites. a Representative traces of spontaneous calcium oscillations in early rings (ER) and early trophozoites (ET) in the presence of Ned-19 or vehicle DMSO. b Bar charts showing the average peak height of the spontaneous calcium oscillations in Ned-19 treated early rings (ER) or early trophozoites (ET) compared to controls. ${ }^{* *} \mathrm{p}<0.01$; ${ }^{* * * *} p<0.0001$. Error bar SEM 
stages of $P$. falciparum asexual cycle. This supports previous findings [6] describing a pivotal role of $\mathrm{Ca}^{2+}$ signalling in the development of $P$. falciparum. In that study, the stage-specific spontaneous $\mathrm{Ca}^{2+}$ oscillations in the intra-erythrocytic stages of $P$. falciparum were inhibited by a specific inhibitor of IP3 (2-APB), resulting in developmental defects and leading to parasite death [6]. Interestingly, in that report and in the present work, the decrease in $\mathrm{Ca}^{2+}$ oscillations caused by 2 -APB and Ned19 at the early ring stage was not sufficient to block parasite development, while ability to affect $\mathrm{Ca}^{2+}$ oscillations later at the trophozoite stage was in both cases associated to an inhibitory effect on the growth of these parasites. The ability of $\mathrm{Ca}^{2+}$ signalling in regulating cellular response in different stages of parasite life cycle relies on a family of $\mathrm{Ca}^{2+}$-dependent protein kinases. Among these, PfCDPK1 (calcium-dependent protein kinase-1) is expressed during the intraerythrocytic schizogony and in the sporozoite stage, and it is crucial for the viability of P. falciparum. Kato and co-workers identified purkalfamine as an inhibitor of PfCDPK1 able to block parasite development at the late schizont stage [41]. It is known that CDPK1 is crucial also in the sexual life cycle stages of Plasmodium berghei, regulating zygote development [42]. Other studies showed that another $\mathrm{Ca}^{2+}$-dependent protein kinase, PfCDPK5, controls parasite egress from erythrocytes [43].

These data altogether highlight the potential impact of $\mathrm{Ca}^{2+}$ signalling antagonists as new antimalarial drugs able to block different stages of the life cycle of P. falciparum. Accordingly, different research groups recently focused their efforts in performing large scale drug screening to identify new compounds able to target $\mathrm{Ca}^{2+}$-dependent protein kinases or more generally $\mathrm{Ca}^{2+}$-signalling in Apicomplexa [44-46]. In this context, the results of this study introduce NAADP signalling as a new potential target for the development of drugs able to impair $\mathrm{Ca}^{2+}$ homeostasis in P. falciparum.

Spontaneous $\mathrm{Ca}^{2+}$ oscillations have been poorly investigated in $P$. falciparum. It has been shown that a specific inhibitor of IP3 (2-APB) was able to block $\mathrm{Ca}^{2+}$ oscillations in ring and trophozoite stages [6], while a selective melatonin receptor antagonist, luzindole, was able to inhibit spontaneous $\mathrm{Ca}^{2+}$ oscillations mainly in the ring stages of the parasite [37]. The result that Ned-19 affects $\mathrm{Ca}^{2+}$ oscillations in early rings and trophozoites suggests that both NAADP and IP3 are involved in this process. This result is consistent with the observations that NAADP induces $\mathrm{Ca}^{2+}$ oscillations in different eukaryotic cell types, from sea urchin eggs [19] to pancreatic acinar cells [47-49], through a two-pool mechanism involving both endoplasmic reticulum-independent NAADPsensitive stores and the endoplasmic reticulum IP3- and
cADPR-sensitive stores [50, 51]. In this model, NAADP is crucial in priming $\mathrm{Ca}^{2+}$-induced $\mathrm{Ca}^{2+}$-Release from endoplasmic reticulum (CICR), through a mechanism of overloading and spontaneous $\mathrm{Ca}^{2+}$ release from these stores [50].

Besides using Ned-19 as a specific inhibitor of NAADP signalling, this compound was used to fluorescently tag the NAADP receptor in living cells [25]. These experiments showed the co-localization of the Ned-19 and the Lysotracker fluorescent signals in different stages of the life cycle of $P$. falciparum, suggesting that yet to be identified NAADP-receptors may localize on acidic compartments also in P. falciparum and possibly in Apicomplexa, similarly to several mammalian cell types $[18,20]$. As however different acidic organelles are labelled by Lysotracker dye in P. falciparum (acidocalcisomes, digestive vacuole and lysosomes), further experiments are needed to identity the Ned-19 positive organelles.

\section{Conclusion}

The ability of the specific NAADP inhibitor Ned-19 to block $P$. falciparum life cycle progression from the trophozoite to the late asexual stages and to affect spontaneous oscillations in the parasite intracellular $\mathrm{Ca}^{2+}$ concentration constitute the first evidence to suggest the presence of the regulatory molecule NAADP and its role in $\mathrm{Ca}^{2+}$ homeostasis in the malaria parasites and more generally in Apicomplexa. The lack of predicted orthologue NAADP receptors in the $P$. falciparum genome suggests that such putative receptors and the NAADP mediated regulatory mechanism(s) in the malaria parasites may considerably differ from those described in distant organisms. This raises the possibility that these yet to be explored cellular mechanism(s) may be targeted with a high selectivity.

\section{Additional files}

Additional file 1: Figure S1. Ned-19 induces morphological changes in the structure of late asexual stages of $P$. falciparum. Late stages parasites were incubated for $6 \mathrm{~h}$ in the presence or absence of $125 \mu \mathrm{M} \mathrm{Ned}-19$ and processed to examine their morphology. A) Samples were Giemsa stained and examined for conspicuous morphological alterations. Representative untreated and treated parasites are shown. Scale bar: $5 \mu \mathrm{m}$. B) Electron Micrographs showing representative DMSO and Ned-19-treated parasites. R: Rhoptry. N: Nucleus. Scale bar: $0.5 \mu \mathrm{m}$.

Additional file 2: Figure S2. Representative examples of asexual parasites. ER: Early rings; LR: Late rings; ET: Early trophozoites; LT: Late trophozoites; ES: Early schizonts; LS: Late schizonts. Scale bar: $5 \mu \mathrm{m}$.

\section{Abbreviations}

$\mathrm{Ca}^{2+}$ : calcium; ATPase: adenosine triphosphatase; PPase: pyrophosphatase; SERCA: sarco/endoplasmic reticulum Ca ${ }^{2+}$-ATPase; IP3: inositol 1,4,5-bisphosphate; CADPR: cyclic ADP-ribose; NAADP: nicotinic acid adenine dinucleotide phosphate; TPCs: two pore channels; VWF: von Willebrand factor; ET-1: endothelin-1; DMSO: dimethyl sulfoxide; ROI: region of interest; SEM: standard 
error mean; IP3R: IP3 receptor; RyR: ryanodine receptor; PfCDPK1: calciumdependent protein kinase-1; CICR: $\mathrm{Ca}^{2+}$-induced $\mathrm{Ca}^{2+}$-release; ER: early rings; LR: late rings; ET: early trophozoites; LT: late trophozoites; ES: early schizonts; LS: late schizonts.

\section{Authors' contributions}

PSC and GG designed and conducted the experiments and drafted the manuscript. AF contributed to design calcium oscillation experiments. FP prepared and analyzed electron micrographs, contributed to design experiments and discussed the manuscript. PA and AF contributed to the experimental design and discussed the manuscript. All authors read and approved the final manuscript.

\section{Author details \\ 1 Dipartimento di Malattie Infettive, Istituto Superiore di Sanità, Viale Regina Elena n. 299, 00161 Rome, Italy. ${ }^{2}$ Department of Vector Biology, Max-Planck Institute for Infection Biology, Charitéplatz 1, 10117 Berlin, Germany. ${ }^{3}$ Depart- ment of Anatomy, Histology, Forensic Medicine and Orthopedics, Section of Histology and Medical Embryology, Sapienza University of Rome, Rome, Italy. ${ }^{4}$ Nucleic Acids Laboratory, Institute of Molecular Biology and Pathology, National Research Council (IBPM-CNR), Department of Biology and Biotech- nologies, Sapienza University, Rome, Italy.}

\section{Acknowledgements}

We thank Dr. M. Sanchez, Istituto Superiore di Sanità, Rome, for FACS analysis and Prof. G. Girelli, Blood Centre of 'Sapienza'University of Rome, for the gift of human red blood cells.

\section{Competing interests}

The authors declare that they have no competing interests.

\section{Availability of data and materials}

The datasets used and/or analysed during the current study are available from the corresponding author on reasonable request.

\section{Consent for publication}

Not applicable.

\section{Ethical approval and consent to participate}

Not applicable.

\section{Funding}

This work was supported in part by the EU FP7 Network of Excellence 'European Virtual Institute of Malaria Research EVIMalaR' (Project No. 242095), the EU FP7 Project 'OzMalNet' (Project No. 269238) and the Bill and Melinda Gates Foundation Grant OPP1040394.

\section{Publisher's Note}

Springer Nature remains neutral with regard to jurisdictional claims in published maps and institutional affiliations.

Received: 15 March 2017 Accepted: 4 September 2017 Published online: 12 September 2017

\section{References}

1. WHO. World malaria report 2016. Geneva: World Health Organization, 2016.

2. Miller LH, Ackerman HC, Su XZ, Wellems TE. Malaria biology and disease pathogenesis: insights for new treatments. Nat Med. 2013;19:156-67.

3. Wasserman M, Alarcon C, Mendoza PM. Effects of $\mathrm{Ca}++$ depletion on the asexual cell cycle of Plasmodium falciparum. Am J Trop Med Hyg. 1982;31:711-7.

4. Wasserman M, Chaparro J. Intraerythrocytic calcium chelators inhibit the invasion of Plasmodium falciparum. Parasitol Res. 1996;82:102-7.

5. Glushakova S, Lizunov V, Blank PS, Melikov K, Humphrey G, Zimmerberg J. Cytoplasmic free $\mathrm{Ca}_{2}{ }^{+}$is essential for multiple steps in malaria parasite egress from infected erythrocytes. Malar J. 2013;12:41.
6. Enomoto M, Kawazu S, Kawai S, Furuyama W, Ikegami T, Watanabe J, et al. Blockage of spontaneous $\mathrm{Ca}_{2}{ }^{+}$oscillation causes cell death in intraerythrocitic Plasmodium falciparum. PLoS ONE. 2012;7:e39499.

7. Docampo R, Moreno SN. Acidocalcisomes. Cell Calcium. 2011;50:113-9.

8. Biagini GA, Bray PG, Spiller DG, White MR, Ward SA. The digestive food vacuole of the malaria parasite is a dynamic intracellular $\mathrm{Ca}^{+}$store. J Biol Chem. 2003;278:27910-5.

9. Krishna S, Woodrow C, Webb R, Penny J, Takeyasu K, Kimura M, et al. Expression and functional characterization of a Plasmodium falciparum $\mathrm{Ca2}^{+}$-ATPase (PfATP4) belonging to a subclass unique to apicomplexan organisms. J Biol Chem. 2001;276:10782-7.

10. Eckstein-Ludwig U, Webb RJ, Van Goethem ID, East JM, Lee AG, Kimura $\mathrm{M}$, et al. Artemisinins target the SERCA of Plasmodium falciparum. Nature. 2003;424:957-61.

11. Scheibel LW, Colombani PM, Hess AD, Aikawa M, Atkinson CT, Milhous WK. Calcium and calmodulin antagonists inhibit human malaria parasites (Plasmodium falciparum): implications for drug design. Proc Natl Acad Sci USA. 1987:84:7310-4.

12. Streb H, Irvine RF, Berridge MJ, Schulz I. Release of $\mathrm{Ca}_{2}^{+}$from a nonmitochondrial intracellular store in pancreatic acinar cells by inositol-1,4,5trisphosphate. Nature. 1983;306:67-9.

13. Lee HC, Walseth TF, Bratt GT, Hayes RN, Clapper DL. Structural determination of a cyclic metabolite of $\mathrm{NAD}+$ with intracellular $\mathrm{Ca}_{2}{ }^{+}$-mobilizing activity. J Biol Chem. 1989;264:1608-15.

14. Lee HC, Aarhus R. A derivative of NADP mobilizes calcium stores insensitive to inositol trisphosphate and cyclic ADP-ribose. J Biol Chem. 1995;270:2152-7.

15. Albrieux M, Lee HC, Villaz M. Calcium signaling by cyclic ADP-ribose, NAADP, and inositol trisphosphate are involved in distinct functions in ascidian oocytes. J Biol Chem. 1998;273:14566-74.

16. Santella L, Kyozuka K, Genazzani AA, De Riso L, Carafoli E. Nicotinic acid adenine dinucleotide phosphate-induced $\mathrm{Ca}\left(2^{+}\right)$release. Interactions among distinct $\mathrm{Ca}\left(2^{+}\right)$mobilizing mechanisms in starfish oocytes. J Biol Chem. 2000;275:8301-6.

17. Navazio L, Bewell MA, Siddiqua A, Dickinson GD, Galione A, Sanders D. Calcium release from the endoplasmic reticulum of higher plants elicited by the NADP metabolite nicotinic acid adenine dinucleotide phosphate. Proc Natl Acad Sci USA. 2000;97:8693-8.

18. Aley PK, Mikolajczyk AM, Munz B, Churchill GC, Galione A, Berger F. Nicotinic acid adenine dinucleotide phosphate regulates skeletal muscle differentiation via action at two-pore channels. Proc Natl Acad Sci USA. 2010;107:19927-32.

19. Cancela JM, Churchill GC, Galione A. Coordination of agonist-induced $\mathrm{Ca} 2^{+}$-signalling patterns by NAADP in pancreatic acinar cells. Nature. 1999;398:74-6.

20. Esposito B, Gambara G, Lewis AM, Palombi F, D'Alessio A, Taylor LX, et al. NAADP links histamine $\mathrm{H} 1$ receptors to secretion of von Willebrand factor in human endothelial cells. Blood. 2011;117:4968-77.

21. Gambara G, Billington RA, Debidda M, D’Alessio A, Palombi F, Ziparo E, et al. NAADP-induced $\mathrm{Ca}_{2}{ }^{+}$signaling in response to endothelin is via the receptor subtype $B$ and requires the integrity of lipid rafts/caveolae. J Cell Physiol. 2008;216:396-404.

22. Alves E, Bartlett PJ, Garcia CR, Thomas AP. Melatonin and IP3-induced $\mathrm{Ca}_{2}^{+}$release from intracellular stores in the malaria parasite Plasmodium falciparum within infected red blood cells. J Biol Chem. 2011;286:5905-12.

23. Garcia CRS, Alves E, Pereira PHS, Bartlett PJ, Thomas AP, Mikoshiba K, et al. InsP3 signaling in apicomplexan parasites. Curr Top Med Chem. 2017;17:2158-65.

24. Jones ML, Cottingham C, Rayner JC. Effects of calcium signaling on Plasmodium falciparum erythrocyte invasion and post-translational modification of gliding-associated protein 45 (PfGAP45). Mol Biochem Parasitol. 2009;168:55-62.

25. Naylor E, Arredouani A, Vasudevan SR, Lewis AM, Parkesh R, Mizote A, et al. Identification of a chemical probe for NAADP by virtual screening. Nat Chem Biol. 2009;5:220-6.

26. Thai TL, Churchill GC, Arendshorst WJ. NAADP receptors mediate calcium signaling stimulated by endothelin-1 and norepinephrine in renal afferent arterioles. Am J Physiol Renal Physiol. 2009;297:F510-6. 
27. Arndt L, Castonguay J, Arlt E, Meyer D, Hassan S, Borth H, et al. NAADP and the two-pore channel protein 1 participate in the acrosome reaction in mammalian spermatozoa. Mol Biol Cell. 2014;25:948-64.

28. Davis LC, Morgan AJ, Chen JL, Snead CM, Bloor-Young D, Shenderov E, et al. NAADP activates two-pore channels on T cell cytolytic granules to stimulate exocytosis and killing. Curr Biol. 2012;22:2331-7.

29. Favia A, Desideri M, Gambara G, D'Alessio A, Ruas M, Esposito B, et al. VEGF-induced neoangiogenesis is mediated by NAADP and twopore channel-2-dependent $\mathrm{Ca}_{2}^{+}$signaling. Proc Natl Acad Sci USA. 2014;111:E4706-15.

30. Walliker D, Quakyi IA, Wellems TE, McCutchan TF, Szarfman A, London WT, et al. Genetic analysis of the human malaria parasite Plasmodium falciparum. Science. 1987;236:1661-6.

31. Lambros C, Vanderberg JP. Synchronization of Plasmodium falciparum erythrocytic stages in culture. J Parasitol. 1979;65:418-20.

32. Nillni EA, Londner MV, Spira DT. A simple method for separation of uninfected erythrocytes from those infected with Plasmodium berghei and for isolation of artificially released parasites. Z Parasitenkd. 1981;64:279-84.

33. Bei AK, Desimone TM, Badiane AS, Ahouidi AD, Dieye T, Ndiaye D, et al. A flow cytometry-based assay for measuring invasion of red blood cells by Plasmodium falciparum. Am J Hematol. 2010;85:234-7.

34. O'Haver T. Peak finding and measurement. https://de.mathworks.com/ matlabcentral/fileexchange/11755-peak-finding-and-measurement (2006). Accessed 10 Jul 2016.

35. Rosen D, Lewis AM, Mizote A, Thomas JM, Aley PK, Vasudevan SR, et al. Analogues of the nicotinic acid adenine dinucleotide phosphate (NAADP) antagonist Ned-19 indicate two binding sites on the NAADP receptor. J Biol Chem. 2009;284:34930-4.

36. Galione A, Morgan AJ, Arredouani A, Davis LC, Rietdorf K, Ruas M, et al. NAADP as an intracellular messenger regulating lysosomal calciumrelease channels. Biochem Soc Trans. 2010;38:1424-31.

37. Furuyama W, Enomoto M, Mossaad E, Kawai S, Mikoshiba K, Kawazu S. An interplay between 2 signaling pathways: melatonin-cAMP and IP3$\mathrm{Ca}_{2}^{+}$signaling pathways control intraerythrocytic development of the malaria parasite Plasmodium falciparum. Biochem Biophys Res Commun. 2014;446:125-31.

38. Cruz LN, Juliano MA, Budu A, Juliano L, Holder AA, Blackman MJ, et al. Extracellular ATP triggers proteolysis and cytosolic $\mathrm{Ca}(2)(+)$ rise in Plasmodium berghei and Plasmodium yoelii malaria parasites. Malar J. 2012;11:69.
39. Nagamune K, Hicks LM, Fux B, Brossier F, Chini EN, Sibley LD. Abscisic acid controls calcium-dependent egress and development in Toxoplasma gondii. Nature. 2008;451:207-10.

40. Plattner H, Sehring IM, Mohamed IK, Miranda K, De Souza W, Billington R, et al. Calcium signaling in closely related protozoan groups (Alveolata): non-parasitic ciliates (Paramecium, Tetrahymena) vs. parasitic Apicomplexa (Plasmodium, Toxoplasma). Cell Calcium. 2012;51:351-82.

41. Kato N, Sakata T, Breton G, Le Roch KG, Nagle A, Andersen C, et al. Gene expression signatures and small-molecule compounds link a protein kinase to Plasmodium falciparum motility. Nat Chem Biol. 2008;4:347-56.

42. Sebastian S, Brochet M, Collins MO, Schwach F, Jones ML, Goulding D, et al. A Plasmodium calcium-dependent protein kinase controls zygote development and transmission by translationally activating repressed mRNAs. Cell Host Microbe. 2012;12:9-19.

43. Dvorin JD, Martyn DC, Patel SD, Grimley JS, Collins CR, Hopp CS, et al. A plant-like kinase in Plasmodium falciparum regulates parasite egress from erythrocytes. Science. 2010;328:910-2.

44. Crowther GJ, Hillesland HK, Keyloun KR, Reid MC, Lafuente-Monasterio MJ, Ghidelli-Disse S, et al. Biochemical screening of five protein kinases from Plasmodium falciparum against 14,000 cell-active compounds. PLoS ONE. 2016;11:e0149996

45. Hui R, El Bakkouri M, Sibley LD. Designing selective inhibitors for calciumdependent protein kinases in apicomplexans. Trends Pharmacol Sci. 2015;36:452-60.

46. Sidik SM, Hortua Triana MA, Paul AS, El Bakkouri M, Hackett CG, Tran F, et al. Using a genetically encoded sensor to identify inhibitors of Toxoplasma gondii Ca2+ signaling. J Biol Chem. 2016;291:9566-80.

47. Aarhus R, Dickey DM, Graeff RM, Gee KR, Walseth TF, Lee HC. Activation and inactivation of $\mathrm{Ca}_{2}{ }^{+}$release by NAADP + . J Biol Chem. 1996;271:8513-6.

48. Genazzani AA, Empson RM, Galione A. Unique inactivation properties of NAADP-sensitive Ca2 ${ }^{+}$release. J Biol Chem. 1996;271:11599-602.

49. Genazzani AA, Galione A. Nicotinic acid-adenine dinucleotide phosphate mobilizes $\mathrm{Ca}_{2}^{+}$from a thapsigargin-insensitive pool. Biochem J. 1996;315(Pt 3):721-5.

50. Churchill GC, Galione A. NAADP induces $\mathrm{Ca}_{2}^{+}$oscillations via a two-pool mechanism by priming IP3- and CADPR-sensitive $\mathrm{Ca}_{2}^{+}$stores. EMBO J. 2001;20:2666-71.

51. Guse AH. Linking NAADP to ion channel activity: a unifying hypothesis. Sci Signal. 2012;5:pe18.

\section{Submit your next manuscript to BioMed Central and we will help you at every step:}

- We accept pre-submission inquiries

- Our selector tool helps you to find the most relevant journal

- We provide round the clock customer support

- Convenient online submission

- Thorough peer review

- Inclusion in PubMed and all major indexing services

- Maximum visibility for your research

Submit your manuscript at www.biomedcentral.com/submit
BioMed Central 